\title{
Canopy architecture and radiation interception measurements in olive
}

\author{
A. Díaz-Espejo, J.E. Fernández, P.J. Durán, I.F. Girón \\ Instituto de Recursos Naturales y Agrobiología, Apartado 1052, 41012-Sevilla, Spain
}

H. Sinoquet, G. Sonohat, J. Phattaralerphong

UMR PIAF, INRA-Université Blaise Pascal. Site de Crouelle. 234, avenue du Brezet

63039 Clermont-Ferrand Cedex 2, France

J.M. Infante, V. Chamorro, L. Villagarcía

Universidad Pablo de Olavide, Dpto. de Ciencias Ambientales, 41013-Sevilla, Spain

M.J. Palomo

E.U.I.T.A., Dpto. de Ciencias Agroforestales, 41013-Sevilla, Spain

Keywords: RATP model, leaf area, transpiration, photosynthesis, digitiser.

\begin{abstract}
In this work we tested techniques suitable for a future validation of the RATP model to simulate transpiration and photosynthesis of mature olive trees under field conditions. Canopy architecture was characterised with an electromagnetic 3D digitiser and the software 3A. Although the capability of the software to deal with big data sets has to be improved, the system seems to meet the RATP requirements. An array of radiation sensors mounted in an aluminium bar and located at different positions within the canopy showed to be an useful tool for monitoring radiation distribution; these data can be used to validate the RATP predictions. Leaves intercepting more radiation showed greater values both of area based nitrogen content and photosynthetic capacity, and the increment of nitrogen was found to be related to the increment in leaf mass area. A method was tested for assessing plant leaf area, which could allow us to determine the leaf area of the biggest trees in the orchard, with reduced time and labour.
\end{abstract}

\section{INTRODUCTION}

Models of water and carbon exchange are useful tools for assessing water use and crop performance as a function of plant characteristics, environmental variables and management practices. The most relevant modeling exercises with the olive tree have been made in recent years. In 1996, Moreno et al., modelled transpiration with a two-big leaves model and compared their results with values of transpiration estimated from sap flow measurements. Mariscal et al., (2000a) proposed a model describing radiation interception by olive trees, especially designed to estimate radiation intercepted at the orchard level. Using this model, Mariscal et al. (2000b) estimated radiation-use-efficiency and dry matter partitioning of a young olive orchard. More recently, Testi et al. (2004) have studied the relationship between evapotranspiration of olive orchards and canopy size using the eddy covariance and the water balance techniques.

Most of the existing information on modeling gas exchange in olive has been obtained in studies at the leaf level (Diaz-Espejo et al., 2002; Moriana et al., 2002). Scaling up from the leaf to the canopy can be done with three-dimensional (3D) models simulating water and carbon exchanges between plants and the atmosphere at the 
intracanopy scale. One of these is the RATP model (Sinoquet et al., 2001), which combines radiation transfer, energy balance and photosynthesis. In RATP, canopy structure is abstracted as an array of 3D cells, the size of which is user-defined according to $x, y$ and $z$-axes. Each occupied cell -some of them may be empty- is characterized by the area density of the canopy components within it -defined as leaves of different ages, woody parts and fruits. The model is fed with data on meteorological variables around the canopy, entered as uniform, vertical profiles or at the 3D cell scale. Properties of the plant components are also needed. All these input data are described by Sinoquet et al. (2001).

The aim of this work was to test techniques used for obtaining the data on tree architecture, foliage distribution, and photosynthesis needed for feeding the RATP model to simulate transpiration and photosynthesis of mature olive trees under field conditions. In addition, we show techniques to estimate leaf area and leaf irradiance distribution. Both variables are simulated by RATP, but we want to be able to assess them, for future comparisons between our observed data and the data simulated by the model.

\section{MATERIALS AND METHODS}

The work was carried out during the irrigation season (May to October) of 2004, in the experimental orchard La Hampa, which belongs to the Spanish Research Council and is located at $15 \mathrm{~km}$ to the south of Seville, Spain. The orchard contains plots with 'Manzanilla' olive trees of different ages, planted at a spacing of $7 \mathrm{~m} \times 5 \mathrm{~m}$.

For characterising the canopy structure we used an electromagnetic 3D digitiser (Fastrak, Polhemus Inc., Cochester, VT, USA), which allowed us to represent the branch architecture (Sinoquet and Rivet, 1997), and the leaf location and orientation (Sinoquet et al., 1998). The device consists of a transmitter that generates orthogonal magnetic fields, and a sensor shaped as a pointer which, when activated within the magnetic field, records the spatial location and orientation of branches and leaves. The location is referred to a fixed three axis coordinate system; the orientation of the pointer is described by three angles, azimuth, elevation, and roll. The spatial distribution of branches - including topological relationships -could then be obtained with the software 3A (Adam et al., 1999). Foliage was recreated by combining both the spatial locations of shoots, as determined from 3D digitising, and foliage reconstruction rules derived from a representative number of digitised shoots (Sonohat et al., 2004). For each shoot, the area and number of leaves attached to the shoot were derived from the above mentioned allometric relationships. Light interception by the 3D-reconstructed trees was computed with the VegeSTAR 3.0 software (Adam et al., 2002). We tested the system with a 15year-old olive tree of about $3.5 \mathrm{~m}$ height, with a single trunk bifurcating in two main branches at $1.2 \mathrm{~m}$ from the ground.

For quantifying the radiation intercepted by the canopy we used an array of 40 photosynthetic photon flux density (PPFD, mol m $\mathrm{m}^{-2} \mathrm{~d}^{-1}$ ) sensors, made from gallium arsenide phosphide (GaAsP) photodiode following detailed instruction of assembly and calibration from Fielder and Comeau (2000). The sensors were mounted in an aluminium bar that was kept horizontal, located at different orientations and heights within the canopy of a 36-year-old tree, of about $4.5 \mathrm{~m}$ height, with a single trunk and two main branches bifurcating at $1.5 \mathrm{~m}$ from the ground. Ten minutes averages were recorded with a Campbell CR10X data logger and an AM25T multiplexer. Measurements took several days of different weather conditions. The relationship between PPFD intercepted by the canopy and the photosynthetic capacity of the leaves was explored by placing one radiation sensor next to each one of the leaves in which $A / C_{i}$ response curves were 
recorded with a portable photosynthesis system Li-6400 (LiCor Inc., Lincoln NE, USA). We chose leaves of different age and position in the canopy of the mentioned tree. To analyse the $A / C_{i}$ response curves we followed the approach suggested by Farquhar et al. (1980), including the potential phosphate limitation presented by Harley and Tenhunen (1991). Photosynthetic capacity was expressed hereafter as the maximum rate of

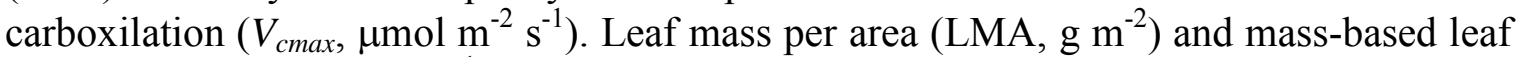
$\mathrm{N}$ concentration $\left(N_{\text {mass }}, \mathrm{g} \mathrm{g}^{-1}\right)$ were measured for each leaf. Dry mass was determined after oven-drying at $80{ }^{\circ} \mathrm{C}$ for two days, and $\mathrm{N}$ concentration was determined using the same method of Harley et al. (1992). Eventually we calculated the area based leaf nitrogen content $\left(N_{a}, \mathrm{~g} \mathrm{~m}^{-2}\right)$, from the LMA a $N_{\text {mass }}$ values.

For estimating leaf area (LA, $\mathrm{m}^{2}$ ), we tested Phattaralerphong and Sinoquet's method (unpublished), which determines LA from digital photographs of the plant. We took eight digital photographs around a 4-year-old potted olive tree, one every $45^{\circ}$ change in orientation. The images were analysed with the Tree Analyser software (Phattaralerphong and Sinoquet, 2004). We recorded the height of the camera from the ground, distance to the plant, elevation angle and focal length, information needed by the software to do the analysis. To validate the results, we estimated the LA of the tree and the average leaf size by defoliating the tree and measuring the dry matter of the leaves, and referring it to the dry matter of a sample of known leaf area (measured with a leaf area meter). In addition, we determined the mean leaf angle with the 3D digitiser. After defoliation, we took another set of 8 photographs of the tree, to estimate the branch area. LA was finally estimated as the difference between plant area values obtained from the leafy and defoliated tree photographs.

\section{RESULTS AND DISCUSSION}

Canopy architecture. Using the 3D digitizer was time consuming, due to the intricate architecture of the olive tree. After recording over 5000 entries, which represented about half of the tree (Fig. 1), the 3A software become unacceptably slow, indicating that its capability to deal with a high number of data points need to be improved. Despite that, our results indicate the technique will allow us to reconstruct the canopy architecture with enough accuracy to meet the RATP model requirements. More work is needed to obtain more detailed foliage reconstruction rules, since the foliage reconstruction we made did not reproduce satisfactorily the actual leaf distribution (data not shown). We are currently working on further developing the foliage reconstruction rules.

Light, nitrogen and photosynthetic capacity gradients within the canopy. The array of PPFD sensors mounted in the aluminium bar seems to be a good tool for quantifying the leaf irradiance distribution within the canopy. Figure 2 shows the differences found between a sunny and a cloudy day. The lowest radiation values shown by the curves far away from the trunk correspond to the high leaf area density in the outer part of the canopy. The maximum irradiance was recorded in the central part of the canopy, due to a gap in the upper part caused by the pruning practices applied in the area. The minimum values observed close to the trunk were due to its shading effect on the sensors close to it. Likely the curves shown in Fig. 2 are detailed enough to validate the simulations of light interception given by the RATP model.

Figure 3 shows two typical $A / C_{i}$ curves, one from a leaf in a sunny position and the other from a shaded leaf. The measurements of $N_{a}$ in locations with contrasting irradiances were positively related to the daily incident PPFD (Fig. 4a). Because most of 
the nitrogen in leaves is invested in the photosynthetic apparatus, we expected leaves with higher $N_{a}$ to show a greater photosynthetic capacity, and this is, in fact, what we found. Thus, Figure $4 \mathrm{~b}$ shows that, as predicted by the theory of optimal distribution of nitrogen and photosynthetic capacity with incident PPFD (Hollinger, 1996), leaves in sunnier locations had higher $N_{a}$ and $V_{\text {cmax }}$. Furthermore, the increment in $N_{a}$ was related to the increment in LMA, suggesting that in olive, most of the light acclimation occurs through changes in leaf morphology, as some authors have found for other species (Niinemets et al., 1998; Han et al., 2003). This could allow us to predict the radiation distribution within the canopy of the olive tree, which could simplify both the PPFD monitoring and the modeling work aimed to scale leaf photosynthesis up to the canopy level.

Leaf area. The LA estimated with the method by Phattaralerphong and Sinoquet (unpublished) described in the previous section was $1.46 \mathrm{~m}^{2}$, while we estimated the actual value to be $1.20 \mathrm{~m}^{2}$. Branch area was estimated to be $0.52 \mathrm{~m}^{2}$. Still, doubt remains on the method being useful with mature trees similar to those of our experimental orchard.

\section{CONCLUSION}

The techniques described in this work seem to be appropriate to validate the RATP model for simulating transpiration and photosynthesis of mature olive trees under field conditions.

\section{ACKNOWLEDGEMENTS}

Thanks are due to the Dirección General de Investigación of the Spanish Ministerio de Ciencia y Tecnología, for funding this work (research project AGL200204048-CO3-01), and to the Junta de Andalucía, for financing a visit of Dr. Sinoquet to our lab. We are also grateful to the staff of the research farm La Hampa, belonging to the Spanish Research Council.

\section{LITERATURE CITED}

Adam, B., Donès, N. and Sinoquet, H. 2002. VegeSTAR - software to compute light interception and canopy photosynthesis from images of 3D digitised plants. Version 3.0. UMR PIAF INRA-UBP, Clermont-Ferrand.

Adam, B., Sinoquet, H., Godin, C. and Donès, N. 1999. 3A - software for the acquisition of plant architecture. Version 2.0. UMR PIAF INRA-UBP, Clermont-Ferrand.

Díaz-Espejo, A., Hafidi, B., Fernández, J.E., Palomo, M.J. and Sinoquet, H. 2002. Transpiration and photosynthesis of the olive tree: a model approach. Acta Horticulturae 586:457-460.

Farquhar, G.D., Von Caemmerer, S. and Berry, J.A. 1980. A biochemical model of photosynthetic $\mathrm{CO}_{2}$ assimilation in leaves of $\mathrm{C} 3$ species. Planta 149:78-90.

Fielder, P. and Comeau, P. 2000. Construction and testing of an inexpensive PAR sensor. Res. Br., Min. For., Victoria, BC. Working Paper 53.

Han, Q., Kawasaki, T., Katahata, S., Mukai, Y. and Chiba, Y. 2003. Horizontal and vertical variations in photosynthetic capacity in a Pinus densiflora crownin relation to leaf nitrogen allocation and acclimation to irradiance. Tree Physiology 23:851-857.

Harley, P.C. and Tenhunen, J.D. 1991. Modelling the photosynthetic response of C3 leaves to environmental factors. p.17-39. In: K.J. Boote and R.S. Loomis (eds.), Modelling crop photosynthesis-from Biochemistry to canopy. American Society 
of Agronomy and Crop Science of America, CSSA Special Publication No.19, Madison, Wisconsin, USA.

Harley, P.C., Thomas, R.B., Reynolds, J.F. and Strain, B.R., 1992. Modelling photosynthesis of cotton grown in elevated $\mathrm{CO}_{2}$. Plant, Cell and Environment 15:271-282.

Hollinger, D.Y. 1996. Optimality and nitrogen allocation in a tree canopy. Tree Physiology 16:627-634.

Mariscal, M.J., Orgaz, F. and Villalobos, F. 2000a. Modelling and measurement of radiation interception by olive canopies. Agricultural and Forest Meteorology 100: 183-197.

Mariscal, M.J., Orgaz, F. and Villalobos, F. 2000b. Radiation-use-efficiency and dry matter partitioning of a young olive (Olea europaea) orchard. Tree Physiology 20: $65-72$.

Moreno, F., Fernández, J.E., Clothier, B.E. and Green, S.R. 1996. Transpiration and root water uptake by olive trees. Plant and Soil 184:85-96.

Moriana, A., Villalobos, F.J. and Fereres, E. 2002. Stomatal and photosynthetic responses of olive (Olea europaea L.) leaves to water deficits. Plant, Cell and Environment 25, 395-405.

Niinemets, Ü., Kull, O. and Tenhunen, J.D. 1998. An analysis of light effects on foliar morphology, physiology, and light interception in temperate deciduous woody specious of contrasting shade tolerance. Tree Physiology 18:681-696.

Phattaralerphong, J. and Sinoquet, H. 2004. Tree analyser: a software to compute tree structure parameters from photographs. In: Proc. $4^{\text {th }}$ Workshop on FunctionalStructural Plant Models (FSPM04), Montpellier, 7-11 June 2004, p. 419.

Sinoquet, H., Le Roux, X., Adam, B., Ameglio, T. and Daudet, F.A. 2001. RATP.: a model for simulating the spatial distribution of radiation absorption, transpiration and photosynthesis within canopies: application to an isolated tree crown. Plant, Cell and Environment 24:395-406.

Sinoquet, H. and Rivet, P. 1997. Measurement and visualisation of the architecture of an adult tree based on a three-dimensional digitising device. Trees: Structure and Function 11:265-270.

Sinoquet, H., Thanisawanyangkura, S., Mabrouk, H. and Kasemsap, P. 1998. Charaterisation of light interception in canopies using 3D digitising and image processing. Annals of Botany 82(2):203-212.

Sonohat, G., Sinoquet, H., Kulandaivelu, V., Combes, D. and Lescourret, F. 2004. Threedimensional reconstruction of partially 3D digitised peach tree canopies. In: Proc. $4^{\text {th }}$ Workshop on Functional-Structural Plant Models (FSPM04), Montpellier, 7-11 June 2004, pp. 6-8.

Testi, L., Villalobos, F.J. and Orgaz, F. 2004. Evapotranspiration of a young irrigated olive orchard in southern Spain. Agricultural and Forest Meteorology 121:1-18. 

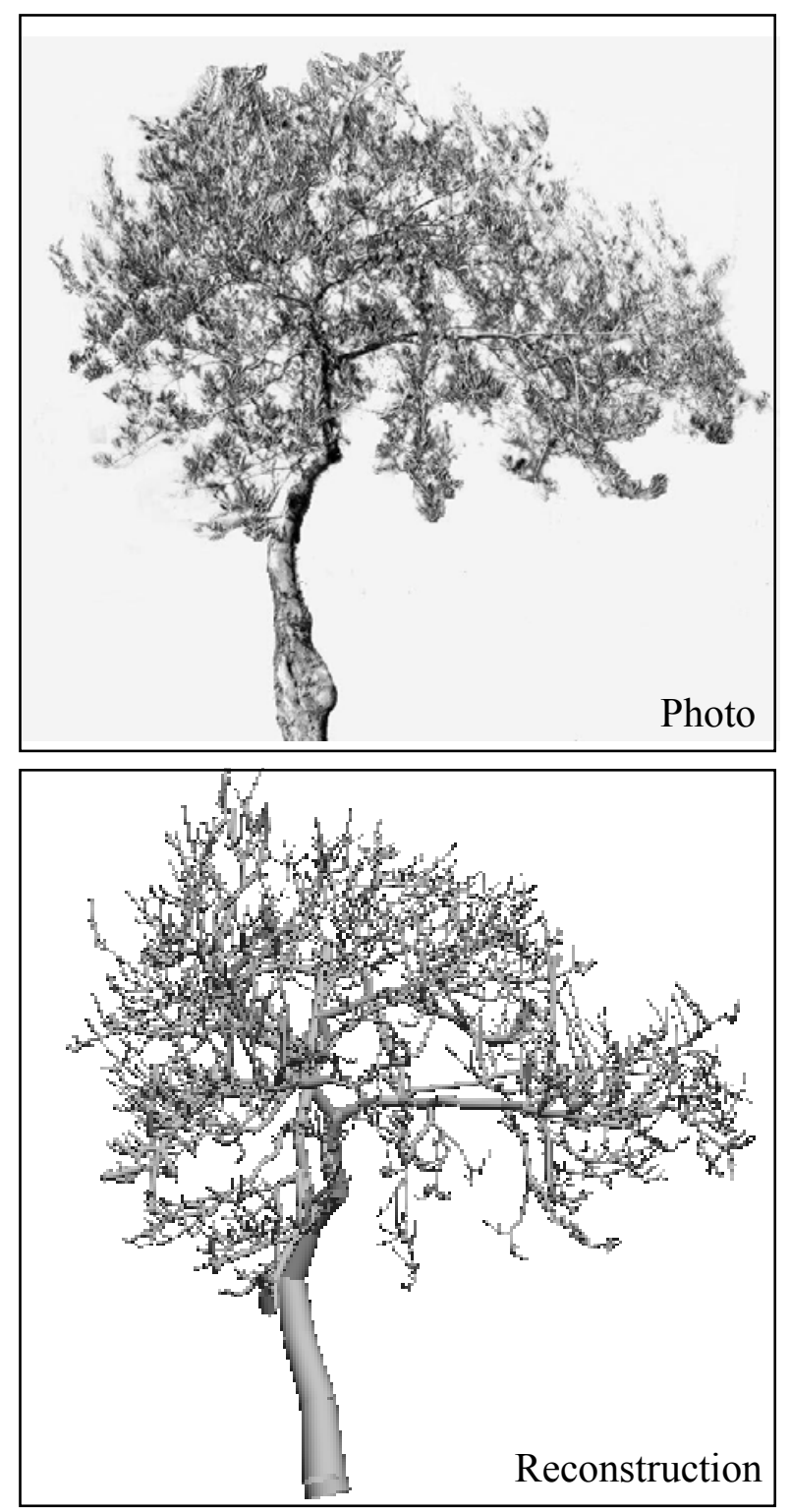

Fig. 1. Photograph of a 15-year-old olive tree, and reconstruction of branches and shoots made with the data collected with the $3 \mathrm{D}$ digitizer and the $3 \mathrm{~A}$ software. 


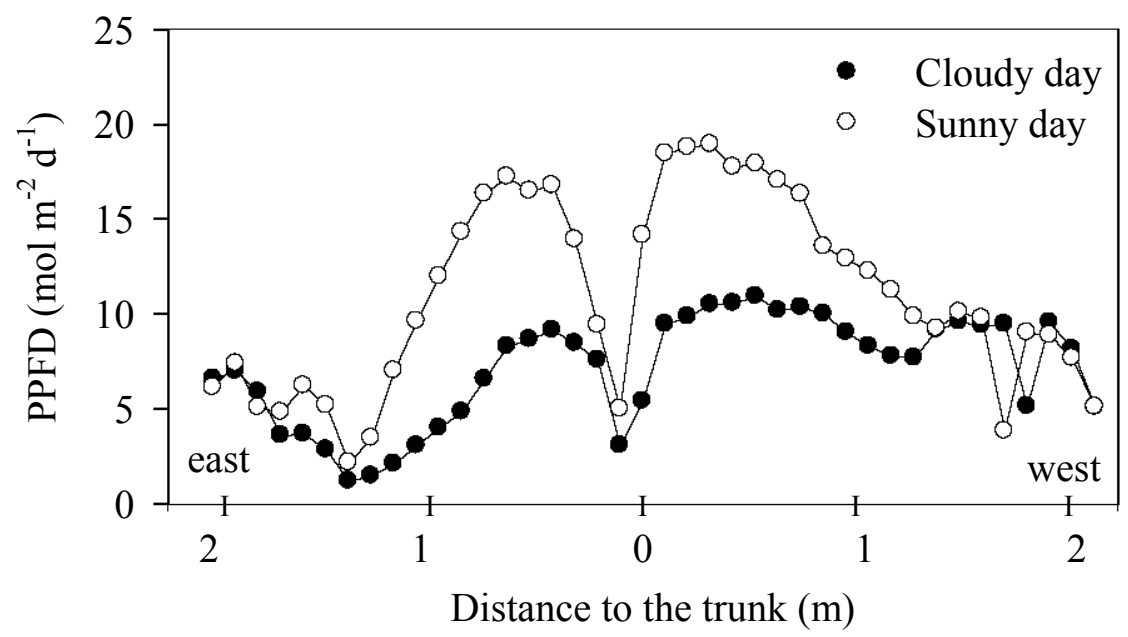

Fig. 2. Cumulative radiation measured by 40 photosynthetic photon flux density sensors (PPFD) within the canopy of a 36-year-old olive tree. The sensors were mounted in an aluminium bar kept horizontal at $1.5 \mathrm{~m}$ height from the ground, oriented from east to west. Measurements were made on a sunny and on a cloudy day, in September 2004. The distances from the edge of the canopy to the trunk were $2.4 \mathrm{~m}$ from the east and $2.8 \mathrm{~m}$ from the west.

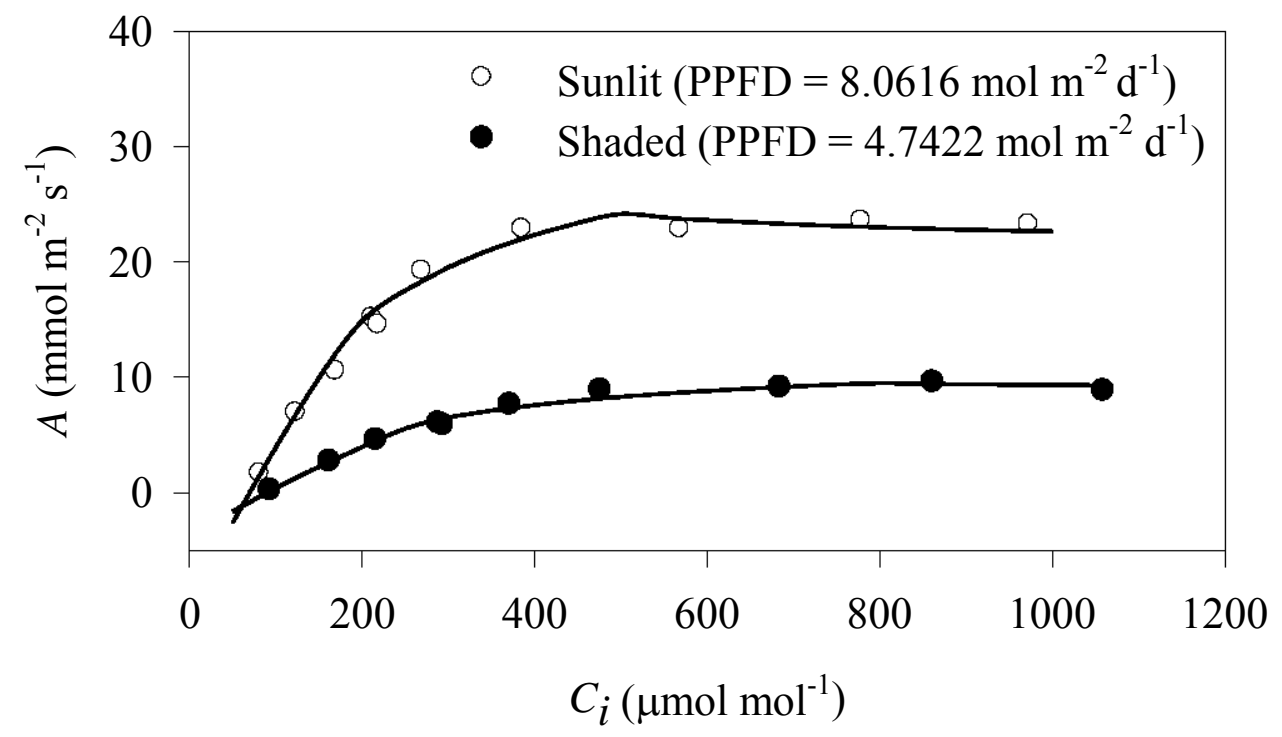

Fig. 3. Two representative $A / C_{i}$ curves at two contrasting light conditions. Lines represent Farquars model fit to measured data (points). PPFD = photosynthetic photon flux density; $A=$ net photosynthesis; $C_{i}=$ internal $\mathrm{CO}_{2}$ concentration. 

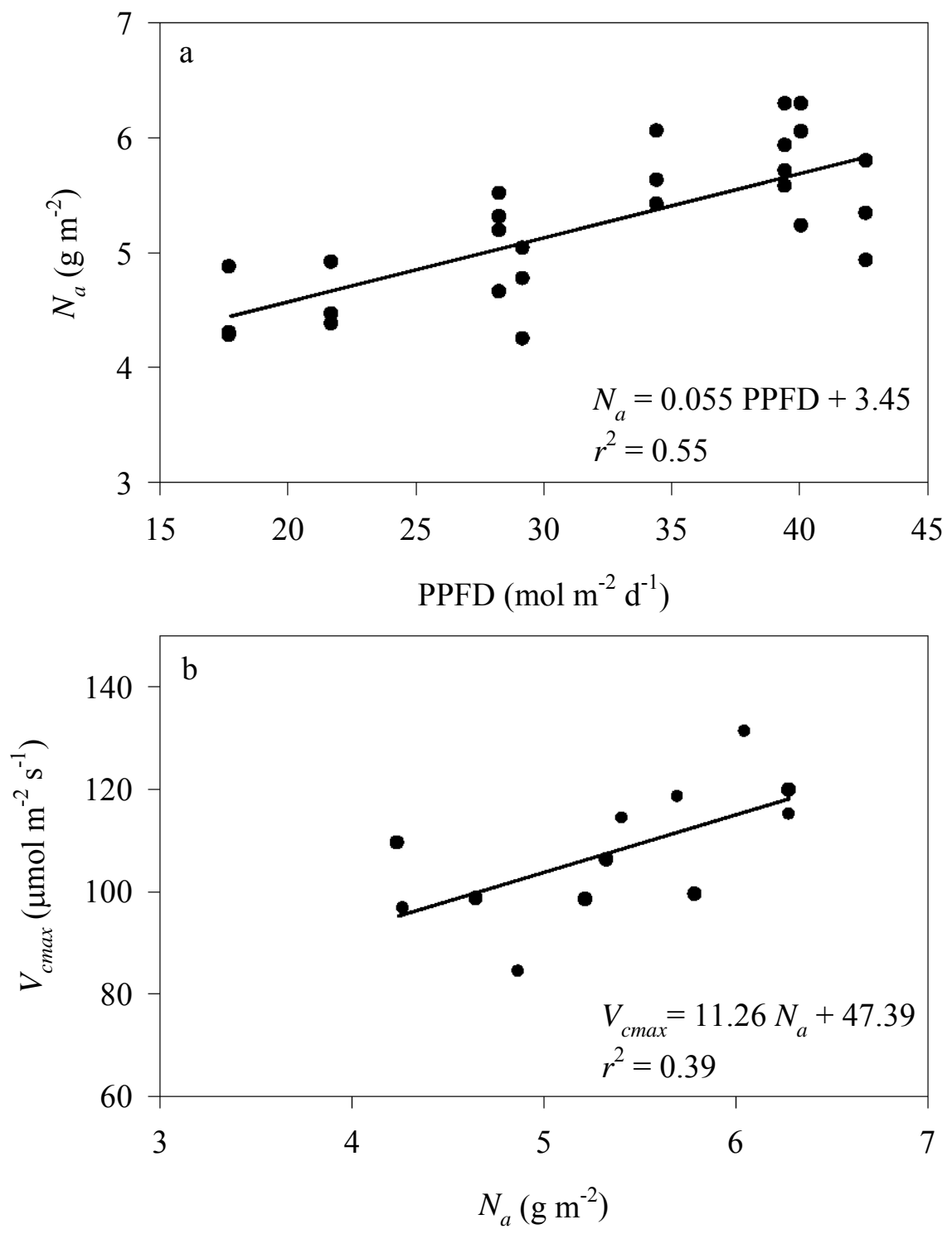

Fig. 4. Relationship between area based leaf nitrogen content $\left(N_{a}\right)$ and daily incident irradiance (PPFD) in the canopy of the experimental olive tree (a). Relationship between photosynthetic capacity expressed as maximum rate of carboxilation $\left(V_{\text {cmax }}\right)$ for leaves with different nitrogen content (b). 